\title{
A INFLUÊNCIA DOS PRINCÍPIOS NAS DECISOES JUDICIAIS
}

Andressa Rangel Dinallo, Samara Monayari Magalhães Silva, Ana Augusta Rodrigues Westin Ebaid.

Universidade do Oeste Paulista - UNOESTE, Presidente Prudente, SP. Curso de Direito- E-mail: andressadinallo@hotmail.com sa_monayari@hotmail.com

\section{RESUMO}

O presente trabalho tem como escopo realizar um exame da importância dos princípios na fundamentação à luz dos princípios constitucionais, o devido processo legal, contraditório, juiz natural e do Estado Democrático de Direito. Com isso, delimitou-se o conteúdo mínimo que uma decisão precisa comportar para ser considerada suficientemente motivada e legitimar a atividade jurisdicional, proporcionando uma tutela jurídica justa, efetiva, tempestiva e adequada. O objetivo deste estudo é apresentar a importância dos princípios como base para as decisões judiciais. 0 método utilizado foi o hipotético dedutivo, este parte de ideias gerais que são aceitas como satisfatórias e a partir disso, é deduzida uma série de suposições que logo se contrastam com os dados concretos da realidade. Este trabalho trata dos princípios norteadores do trâmite judiciário, onde se destaca a relevância dos mesmos na aplicabilidade para se obter uma prestação jurisdicional mais justa e eficiente.

Palavras-Chave: Princípios Constitucionais; Decisões Judiciais; Fundamentação das Decisões; Novo Diploma Processual.

\section{THE INFLUENCE OF PRINCIPLES ON JUDICIAL DECISIONS}

\begin{abstract}
The purpose of this paper is to examine the principle of justification in the light of constitutional principles - due to legal process, contradictory, natural judge - and the Democratic State of Law. This delimited the minimum content that a decision must include to be considered sufficiently motivated and to legitimize the judicial activity, providing a just, effective, timely and adequate legal protection, that affects not only the procedural subjects, but the society as inspector of the Judicial function. The purpose of this study was to present the importance of principles as the basis for judicial decisions. The method used was the hypothetical deductive, this part of general ideas that are accepted as satisfactory and, from this, a series of assumptions are deduced that soon contrast with the concrete facts of reality. The present paper deals with the guiding principles of the judicial process, in which the relevance of the same in the applicability is emphasized to obtain a fairer and more efficient judicial rendering.

Keywords: Constitutional Principles; Judicial Decisions; Rationale For Decisions; New Procedural Law.
\end{abstract}




\section{INTRODUÇÃO}

Não rara às vezes, retoma-se a importância dos princípios nas decisões judiciais, sendo estes fundamentos que direcionam as atitudes tomadas por pessoas que convivem no âmbito jurídico. Com o advento do atual Código de Processo Civil, houve grande discussão sobre os novos princípios, podendo ser citado sucintamente como exemplo o princípio da fundamentação das decisões judiciais.

De acordo com os ensinamentos de Ada Pellegrini Grinover (2014), considerando os escopos sociais e políticos do processo e do direito em geral, além de seu compromisso com a moral e a ética, atribui-se grande relevância aos princípios que não se prendem a dogmática jurídica, mas trazem em si conotações éticas, sociais, e políticas e valem como algo externo ao sistema processual.

Ao longo dos séculos, inúmeras foram às concretizações do devido processo legal que se incorporaram ao rol das garantias mínimas que estruturam o devido processo. Não é lícito, por exemplo, considerar desnecessário o contraditório ou a duração razoável do processo, direitos fundamentais inerentes ao devido processo legal. Nem será lícito, retirar agora os direitos fundamentais já conquistados.

Como bem preleciona Fredie Didier (2015) o processo para ser devido, há de ter atributos, e cada novo atributo corresponde a um princípio constitucional, que embora algumas vezes implícito é de grande relevância. Surgem então, os princípios da adequação, da boa fé processual e da efetividade que são corolários ao devido processo legal.

\section{OBJETIVO}

Cumpre observar que o objetivo da pesquisa é compreender a influência dos princípios nas decisões judiciais e identificar sua atuação nos procedimentos do nosso ordenamento jurídico.

Ademais, necessário se faz o entendimento acerca da análise histórica dos princípios e suas aplicações, tendo em vista que são considerados meios de garantia e democracia no poder judiciário.

Igualmente, se faz oportuno demonstrar a breve história sobre os princípios constitucionais, descrever quais são os mais aplicados, desenvolver a importância e função no caso concreto, identificar os princípios constitucionais implícitos e explícitos garantidos aos cidadãos no ordenamento jurídico, bem como interpretar a motivação das decisões judiciais.

\section{METODOLOGIA}

O método utilizado no presente trabalho foi o hipotético dedutivo, este parte de ideias gerais que são aceitas como satisfatórias e, a partir disso, é deduzida uma série de suposições que logo se contrastam com os dados concretos da realidade. A ideia básica deste método é dar o primeiro passo metodológico dos fatos específicos partindo do geral para o particular. Podendo ser identificada, uma vez que há uma ideia que atua como suposição e que significa a existência de uma hipótese explicativa.

\section{DISCUSSÃO}

O Devido Processo Legal surgiu em 1354 d.C., a partir do rei Eduardo III, rei da Inglaterra. Este decreto inspirou a Magna Carta de 1215, pacto entre o rei João e os barões. A Magna Carta é o documento histórico mais normativo de consagração do devido processo legal, teve fundamental importância na formação dos direitos inglês e estadunidense.

De acordo como inciso LIV do art. 5으 da Constituição Federal "ninguém será privado da liberdade ou de seus bens sem o devido processo legal". Este princípio confere a todo sujeito de direito, no Brasil, o direito a um processo devido, ou seja, o mais justo possível. 
O devido processo legal, assim como os demais princípios, possui como um dos objetivos restringir o poder coercitivo estatal e sanar equívocos, com intuito de que respeite garantias e cumpra exigências inerentes à manutenção do Estado Democrático de Direito. Dessa forma, o princípio do devido processo legal assegura às partes o exercício de suas faculdades e interesses (direito público subjetivo) e perpetua o correto exercício da jurisdição.

Este princípio é conceituado em dois aspectos, o primeiro, substancial, onde o processo legal é uma forma de garantir o acesso à justiça a todos àqueles que sejam titulares de uma posição jurídica num processo judicial ou administrativo. Além disso, é uma forma de proteger os direitos fundamentais do cidadão. De modo secundário com a visão voltada para o aspecto processual, o devido processo legal possui significado mais restrito, porém, não menos relevante.

O procedimento tem aspecto externo, se caracteriza pela sequência dos atos na relação jurídica processual, facilmente confundido com o processo que é o meio de solucionar conflitos, instrumento de jurisdição, visto que é através dele que se cumpre a função jurisdicional.

Deste modo, o contraditório efetivo e a fundamentação das decisões judiciais ao impedir o subjetivismo judicial, atendem ao princípio do devido processo legal. É justamente por meio da fundamentação das decisões, que as partes podem fiscalizar e aceitar a atuação do magistrado.

O devido processo legal possibilita o maior e mais amplo controle dos atos jurídico-estatais, nos quais se incluem os atos administrativos, gerando uma ampla eficácia do princípio do Estado Democrático de Direito, no qual o povo não só se sujeita a imposição de decisões como participa ativamente delas.

Outro princípio que deve ser muito bem lembrado é o princípio da Boa Fé, que sobreveio do artigo 1으. III, da Constituição Federal, no qual, consagra o princípio da dignidade da pessoa humana, que se irradia por todo o ordenamento jurídico, bem como é possuidor de várias faces, dentre elas encontra-se a exigência de tratamento digno entre os sujeitos processuais e terceiros, ou seja, deve-se tratar com boa-fé, que nesse caso, deve ser entendida como uma norma de conduta.

\section{NESTE SENTIDO A DOUTRINA ENSINA}

O princípio da boa-fé extrai-se de uma cláusula geral processual. A opção por uma cláusula geral de boa-fé é a mais correta.É que a infinidade de situações que podem surgir ao longo do processo torna pouco eficaz qualquer enumeração legal exaustiva das hipóteses de comportamento desleal.Daí ser correta a opção da legislação brasileira por uma norma geral que impõe o comportamento de acordo com a boa-fé. (DIDIER, 2015, p.104)

$\mathrm{O}$ auge deste princípio se deu por uma expansão da exigência de boa-fé do direito privado ao direito público, ele se expandiu para todos os ramos do direito, mesmo os não civis. Quando há um vínculo jurídico, as pessoas envolvidas estão obrigadas a não frustrar a confiança razoável do outro, devendo comporta-se como se pode esperar de uma pessoa de boa-fé.

Vale ressaltar que a boa-fé é um importante princípio jurídico, que serve também como fundamento para a manutenção do ato viciado por alguma irregularidade. A boa-fé é um elemento externo ao ato, na medida em que se encontra no pensamento do agente, na intenção com a qual ele fez ou deixou de fazer alguma coisa. Na prática, é impossível definir o pensamento, mas é possível aferir a boa ou má-fé, pelas circunstâncias do caso concreto.

É de conhecimento geral que o direito processual civil ressalta a importância do princípio da efetividade, este ganhou status de princípio constitucional após 16 anos de tramitação no congresso da EC no. 45/2004, ao incluir o inciso LXXVIII, no art. 5ㅇ, da CF, criando como direito individual "a razoável duração do processo e os meios que garantam a celeridade de sua tramitação".

Este princípio deve ser observado como uma garantia de acesso a ordem jurídica justa. Dessa forma, o direito a sentença deve ser visto como o direito ao acolhimento e aos meios 
executivos capazes de dar efetividade ao direito substancial, significando o direito á efetividade em sentido estrito.

Atualmente, o processo judicial brasileiro em todo o seu contexto tem como um de seus maiores problemas a ausência de tempestividade, ao qual tem sido inerente a tutela jurisdicional.

O exorbitante tempo para julgamento de um processo é causa de influência na efetividade da prestação jurisdicional. Dentre os princípios constitucionais orientadores do processo passa-se a dar maior atenção à efetividade, visto a relação que guarda com o tempo para o julgamento de um processo.

O artigo 5ำ, inciso LIX, da Constituição Federal de 1988, dispõe que "ninguém será privado da liberdade ou de seus bens sem o devido processo legal" e, em outros dispositivos legais, permite outorgar que o princípio em estudo destaca um conjunto de garantias processuais que possibilitam um processo justo e gerador de decisões legítimas. È nesse contexto constitucional que o princípio do devido processo legal liga-se à justiça, à efetividade e à presteza da tutela jurisdicional.

É notória a relevância do princípio da celeridade processual, que adentrou no ordenamento jurídico de forma expressa através da Emenda Constitucional $n^{\circ} 45$, de 31 de dezembro de 2004 (art. $5^{\circ}$, LXXVIII).

Seu cumprimento já se fazia obrigatória, porém, desde 1992 com a publicação do Decreto $n^{\circ}$ 678/92 que promulgou o Pacto de San José da Costa Rica, incorporando-se ao nosso ordenamento brasileiro (art. $5^{\circ}, \S 2^{\circ}$ da CF).

Com o advento do pacto, exigiu-se uma duração razoável do processo, desde o momento em que é iniciado até o trânsito em julgado, seja na via judicial, seja na via administrativa. $O$ que se espera é que o julgador conduza a demanda visando refutar incidentes desnecessários, aproveitando sempre que possível, os atos processuais, a instrumentalidade das formas e a economicidade.

O Princípio da Celeridade tem grande ligação com o devido processo legal, pois possibilita a todos, no âmbito judicial e administrativo, o direito a um processo célere, entretanto, com duração admissível, sendo capaz de satisfazer e corrigir efetivamente os interesses a serem alcançados, sem prejudicar ao mesmo tempo as garantias que assistem aos sujeitos do processo.

Constata-se que a celeridade processual deve ser aplicada em consonância com o princípio da fundamentação dos atos decisórios, cada qual com a sua funcionalidade e operabilidade no caso concreto, podendo conviver harmonicamente.

Outro princípio que muito se debate é o princípio do Contraditório, ressalta-se que está fortemente correlacionado à noção de bilateralidade que deve existir no processo, seja no contencioso ou na jurisdição voluntária e na ação em seu sentido amplo. Isto porque a demanda é protagonizada, em regra, pelo menos por dois sujeitos principais: autor e réu, que devem deduzir a sua pretensão e participar de todos os atos do processo em igualdade de condições.

Em síntese, pode-se elencar que o contraditório e a ampla defesa são instrumentos de realização da democracia e do acesso à justiça postos à disposição das partes para tutelar suas pretensões. Consistem em direito de participação ativa e de conhecimento de todos os atos processuais, com a possibilidade de influir na cognição do magistrado, sob pena de descumprimento da sua função jurisdicional. O processo que se desenvolver sem a observância do contraditório e da ampla defesa culminará com a prolação de sentença desmotivada ou com fundamentação insuficiente, posto que foi subtraído o direito das partes de alegarem e provarem seus argumentos com poder de influir no resultado do julgamento. A decisão não terá se debruçado, portanto, sobre todos os aspectos relevantes da demanda, faltando-lhe o conteúdo mínimo exigido pelo art. 93, IX da Constituição Federal.

Por fim, ao cuidar do princípio do Juiz Natural, vale ressaltar que não se encontra expresso no nosso ordenamento jurídico, mas pode ser extraído de dois preceitos constitucionais, são eles 
o art. $5^{\circ}$, XXXVII, que veda a existência de juízo ou tribunal de exceção e o art. $5^{\circ}$, LIII que preconiza que "ninguém será processado nem sentenciado senão pela autoridade competente". Precipuamente, o princípio se desenvolve na observância da imparcialidade do magistrado e na sua independência. Ademais, garante que sua função é legítima e não obstante a liberdade, outorgada em virtude do livre convencimento (art. 131, CPC) a decisão será proferida sem arbitrariedades e nos limites estabelecidos pelo ordenamento jurídico.

O livre convencimento autorizado pelo art. 131 do CPC, só pode ser abordado dentro dos parâmetros legais e razoáveis estabelecidos, aplicando-se a observância do princípio da motivação dos atos decisórios, sob pena de se configurar abuso do poder e das prerrogativas que lhes são conferidas.

Em suma, é neste contexto de seriedade e fundamentação, que se insere o dever de motivação dos atos decisórios, funcionando como instrumento legitimador da função estatal, visando coibir a arbitrariedade judicial.

\section{CONCLUSÃO}

Pode-se concluir que os Princípios do Código de Processo Civil são indispensáveis para melhor aplicação das leis ao caso concreto, objetivando sanar as lides e resolver os interesses de maneira justa e célere.

Deste modo, demonstra-se que o direito processual, bem como todo o ordenamento jurídico brasileiro está disciplinado em diversos princípios que direcionam e regulam os atos processuais, assim é incontestável a sua presença no próprio direito material.

Verifica-se a extrema relevância que tais princípios possuem, tendo em vista que os mesmos podem mudar extinguir e criar todo um procedimento que certamente irá influenciar no resultado final do procedimento processual.

Outrossim, a pesquisa realizada tem como escopo mostrar a efetividade dos princípios no ordenamento jurídico, ao serem aplicados servindo assim como base para tornar as decisões judiciais que visam orientar na busca e melhoria da Justiça como um todo. Portanto, constituem o alicerce do ordenamento jurídico brasileiro.

\section{REFERÊNCIAS}

BRASIL. Constituição (1988). Constituição da República Federativa do Brasil. Brasília: Senado Federal, 1988.

CINTRA, Antonio Carlos de Araújo; GRINOVER, Ada Pellegrini; DINAMARCO, Cândido Rangel. Teoria Geral do Processo. 31a ed. rev. e amp. São Paulo: Malheiros Editores, 2015.

CORDEIRO, Paulo Machado. A responsabilidade social dos juízes e a aplicação dos direitos fundamentais. Salvador: Jus Podivm, 2007.

DIDIER JR., Fredie. Curso de Direito Processual Civil: Introdução ao Direito Processual Civil, Parte Geral e Processo de Conhecimento. Vol. 1. 17a ed.. Salvador: Jus Podivm, 2015.

PELLEGRINI, Ada Grinover. Teoria Geral do Processo, vol. 1, 30a edição, São Paulo: Malheiros Editores, 2014. 